\title{
Discussion on the Ecological Concern of Preschool Teacher Continuing Education
}

\author{
Shaohua Nie \\ (Elementary Education College of Linyi University, Linyi Shandong 273400, China)
}

Keywords: continuing education ecological concern absent innovation

\begin{abstract}
The continuing education of preschool teachers urges for further improvement and promotion. This essay surveys the continuing education of preschool teachers in the perspective of ecology. The current utility and mission oriented preschool teacher continuing education is paying unduly attention to the theoretical knowledge indoctrination and the generality cultivation while neglecting the subject consciousness, practice and personality concern. Neither the trainers nor the trainees can develop in harmony. The continuing education of preschool teachers should build the idea of ecological concern which persists from curriculum design to mode innovation.

Ecological concern, which tries to survey the ecological field in the perspective of ecology in constructing the members of the field into a new system to focus on the positive, active, healthy and harmonious development of every member, is a new topic comes from educational concern and humanistic concern.

The core idea of ecological concern is to focus on the aspiration of the members for development to help them enjoy happy lives, in which they seek natural, healthy and harmonious development. Ecological concern on the continuing education for preschool teachers is to survey the education in the perspective of ecology to build a new system of preschool teacher continuing education. It is the microscopic embodiment of ecology theories in preschool teacher continuing education.
\end{abstract}

\section{The absent of ecological concern for preschool teacher continuing education}

The absent of ecological concern exits in the current preschool teacher continuing education and expresses in the following facts.

\section{Unduly theory indoctrination with insufficient practice}

At present, preschool teacher continuing education is mostly organized in the forms of in-service training, mid-career training, professional titles evaluation, kindergarten director training, kindergarten-based training and so on. Wile influenced by the trend of praising high education background and high professional titles, some kindergartens had employed several teachers with high degrees; there are still teachers of low quality and low education background.

Training organizations providing continuing education for preschool teachers, however, have theoretical courses far from the reality of preschool education. Courses with superior difficulty and full of theories can do little to the improvement and promotion to the knowledge or the professional quality of preschool teachers.

The study of Houqin Liu revealed that due to the large proportion of theoretical courses and art skill courses, courses of high practicality focusing on the teaching skills are insufficient. The lack of courses focusing on teacher morality cultivation and infant mental health intensifies the absent of comprehensive teaching contents, especially the humanities and social sciences and natural science. Most courses in the continuing education of preschool teachers fail to have close relation with actual teaching due to the teaching contents with strong theoretical property and academic nature while low practicality. Preschool teachers are having difficulty not only in understanding the essence of teaching theories, but also overstepping the gap between theory and practice [1].

The unduly theory indoctrination regards preschool teachers receiving training only as knowledge containers rather than real person, therefore paying little attention to their requirements. 


\section{More casual organizations with less coherent system}

The organizations of continuing education for preschool teachers are mostly included in the continuing education organization for primary and secondary school teachers. Factors such as complicated constitution of preschool teachers lead to the casualness of continuing education organization.

While related organizations have been built and cycle plans have been made, detailed duties and content arrangements still urge long-term planning. In the continuing education for preschool teachers, the lack of active incentive policies weakens the enthusiasm of teachers, only to take part in for some situations such as professional titles evaluation and post position.[2]

Therefore, preschool teachers tended to choose quick method when choosing the subjects and forms of continuing education while neglecting practicality. The training they received can hardly promote their teaching ability. This gives the green light to unplanned continuing education.

\section{Too much generality cultivation with little personality development}

The content of continuing education is a Procrustean bed restricting the personality of preschool teachers. Preschool teachers have the most uneven formal schooling among all groups of teachers, ranging from postgraduates to middle school graduates. While kindergartens of different qualities run parallel to each other. A complicated teaching group needs corresponding varied teachers' continuing education.

In the real educational training, however, theories are simply instilled rather than explained and demonstrated. The simple and obsolete teaching method fails to help teachers fully participate in the teaching activities of continuing education. While many lively teaching methods with strong practicality, such as role playing, case teaching, and which can improve the teaching skills and actual managing abilities of the trainees, are hardly applied in continuing education.

Personality development is almost lost in this training mode, which can only develop well-behaved preschool teachers that cannot adapt themselves to the development of preschool education.

\section{More rigid evaluation than flexible assessment}

Corresponding evaluation, an important part of continuing education, is also needed by preschool teacher continuing education. In the real work of preschool teacher continuing education, especially those for improving education background, the current evaluation system pays little attention to the real situation of the trainees in regarding them as the pure acceptor in the teaching process and the container of knowledge.

Either the method of homework plus tests or with course-completion papers are only mechanic cope with no incentives as tests are like transcriptions while papers are like copying and pasting games. Preschool teachers can hardly develop in this kind of continuing education.

Evaluation system of preschool teacher continuing education should be reasonable and scientific, a flexible evaluation system considering the complicated situation of kindergarten education would help improve the potency of continuing education and meanwhile promote the activeness and creativity of the teachers receiving the continuing education.

\section{Discussion on the reasons causing the lack of ecological concern on preschool teacher continuing education}

We are now discussing the lack of ecological concern on preschool teacher continuing education in the perspective of ecological concern in a time when ecological theories have been widely applied in the field of education. There are several reasons. 


\section{Utilitarianism}

With the rapid development of commercialized economy since the 1980s, a value trend of universal utilitarianism has gradually become popular. Influenced by this value reform, continuing education for preschool teachers is also infected by this value trend orienting utilitarianism.

Preschool teacher continuing education, part of the education system, should shoulder the responsibility of promoting human development and help human become a real human. Impacted by utilitarianism, however, preschool teacher continuing education diverges from the original essence of education into a utilitarianism oriented education focusing only on improving educational background and theory incarnation. Furthermore, some training organizations take profits as their only goal and rarely consider the effects of the trainings.

Therefore, the original intention of preschool teachers receiving continuing education is to improve the education background and to promote professional titles while putting the development of professional skills into the second place.

The idea of utilitarianism influences the value judgment of both the trainers and trainees of preschool teacher continuing education, leading to the neglect of human existence and the harmonious development of human life.

\section{Doctrine of projecting}

In the process of preschool teacher continuing education, both the trainers and the trainees hold the same idea that continuing education is a project and a task has to be completed. Restricted by the problems such as insufficient funds, teachers receiving training would rather regard continuous education as a task arranged by the upper level than their own rights and duties.

Some preschool teachers with this attitude think that mere participation in learning activities organized by kindergartens or upper authorities would be enough for continuing education. They study for certifications, higher education background and a promise for future promotion. This also leads to the superficialness and interest orientation of preschool teacher continuing education.

Continuing education of preschool teachers should focus on the well planned self-learning activities with clear object to help them build the idea of lifelong learning and lifelong teaching, therefore help them realize that continuing education should be an idea go through their whole life.

\section{Doctrine of knowledge}

Knowledge is the summary of understanding and experience of human reforming the world. Knowledge concerning different subjects in education is the reliable experience system accumulated in this field. The improvement of human knowing and reforming the world is the result of deepened learning.

Influenced by this idea, knowledge becomes the only poise and test standard in continuing education for preschool teachers. For a long time, China's educators educate only for knowledge, and scholars learn only for knowledge. Humans receiving education are actually neglected, not to mention the individual life value, as attention is paid only to the accumulation of culture knowledge and experiences.

Teaching content in preschool teacher continuing education is knowledge, the richest resource in teaching, the abundant teaching experiences of preschool teachers, is neglected.

\section{Loss of subjectivity}

Subjectivity is the conscious awareness of the subject position, subject ability and subject value of human act as the subject of understanding and practicing. It is the conscious premise for the real body being of human as well as the internal conditions helping human actively and consciously develop subjectivity. [3]

Impacted by the above ideas, directors of preschool teacher continuing education regard knowledge and training as the priority and treat the education as the process only for task 
completion and knowledge indoctrination. Subjectivity conscious is weakened in neglecting the body being of both the trainers and trainees.

Preschool teachers receiving education, however, wrongly treat the continuing education as the process of getting promotion promise and credit hours in losing their subjectivity. Dominated by this idea, there is only mechanic coping and no harmonious developing.

\section{The construction of ecological concern on preschool teacher continuing education}

The ultimate goal of ecological concern is the harmonious development of the body and soul. We think that preschool teacher continuing education should build the correct idea of ecological concern at first.

\section{Build the idea of ecological concern}

First is to get harmonious coexistence. Harmony culture is the core idea of Chinese traditional culture, and education should therefore be a harmony education. Confusions said that a gentleman gets along with others, but not necessarily agree with them. The idea of harmony without sameness recognizes the variety of the world. There are surely differences between things, but the whole phenomenon is in harmony. Harmony is the core of the development of everything.

The core idea of ecological concern is harmonious coexistence, which seeks a condition and an order in harmony to promote the development of preschool teachers. Existence here is a kind of development.

Second is to express natural formation. Generative learning theory consider the generative process, in which learners combine their former cognitive structure with the information they received from the environment, is a process learners actively choose and construct the meaning of information.

Wittrock, the advocator of generative learning theory, proved that the learners' learning is based on their former knowledge and experiences in his experiments. In the process of learning, the active construction of students could help them understand and master the contents they learn. This theory provides referential ideas for preschool teacher continuing education.

The third is to realize equal dialogue. Dialogue, a basic human psychological demand and an effective problem solving method, is the core concept of modern dialogue education theory. The dialogue we emphasize is never the ordinary conversation between two or more people, but the common struggle for the same pursuits and careers.

Equal dialogue is the multi-dimensional interaction between teachers with students, students with students, students with texts and so on. In this practice, teachers and students trust each other and can say whatever they want. The bound of authorities disappeared. Dialogue inevitably breaks the features of the old indoctrination education and combines teachers and students together to help them get common and harmonious development.

\section{Set curriculum on ecological concern}

The diversity of preschool teacher continuing education decides the diversity of curriculum. Continuing education for preschool teachers should meet the learners' requirements with various curriculums.

First is to set regional curriculums according to regional differences. In areas with under-developed kindergartens, old education ideas and insufficient education resources, curriculum in continuing education should focus on the education idea reforming, teaching skills training, modern education technology application and how to make local courses using the local resources.

In cities and towns with advanced kindergartens, new education ideas and abundant education resources, continuing education should then set curriculums analyzing new ideas, promoting 
teaching skills and properly applying educational technologies. This would help avoid wasting curriculum setting and play the full role of the curriculum.

Second is to set post curriculum according to different posts. Preschool teachers with different posts shouldering different duties have different requirements on continuing education. Director training, for example, aims at the kindergarten directors who can have courses such as kindergarten management, pre-school education research, kindergarten education evaluation, etc.

As for ordinary pre-school teachers, courses such as modern pre-school education theory, preschool teacher action research, reform trend in and out of China, application of multi-media technology and vocational skills training should be set to cultivate all-round and featured teachers.

Third is to set layered curriculum according to stage differences. Preschool teacher continuing education should set layered curriculum according to the features of different layers to have layered cultivation.

For teachers who are still struggling for life and are doubtful about their potency for this job, curriculum should include professional morality of preschool teachers, the ordinary daily life of a kindergarten, game organizing, basic skill training and multi-media operation.

For teachers paying attention to the development of preschool education, teaching effects should be emphasized. Courses should include teacher morality research, preschool education research, preschool education laws, special lectures on different topics and advanced teaching skills training in music, art and dancing.

For teachers focusing on students, there should be more comprehensive and researching courses.

\section{Implement multivariate innovation mode}

Ecological concern on preschool teacher continuing education can only be realized with the cooperation of multivariate innovation mode.

First is the self-learning mode innovation. Self-directed reading asks the preschool teachers to choose and arrange their reading in free time. Classic works, related information online and videos of excellent teachers could all help them write notes. This flexible method has no limitation on time or place.

Second is the question mode innovation. One of the modern education concepts is that students construct their own knowledge system communicating with questions. Most of the students' learning is based on question solving, the key of which is how to promote the knowledge system construction when questioning to combine the old and newly learn knowledge together to deepen their understandings.

The key to a successful question solving learning is to create an effective question mode, which should build on the basis of students' understandings. Students realizing their ignorance and defects in knowledge can then break the bound of their former knowledge to research, to discover and to construct the newly learned.

Third is the contextual mode innovation. Situated cognition theories think that only thoughts and learning in special situations make sense. Situation is fundamental to all cognitions and any learning activities separated from condition are valid.

Situated cognition theory gives references to our preschool teacher continuing education that it is not the knowledge memorized in teaching counts, but the knowledge produced in the situation make sense. Situations of preschool teacher continuing education include real physical situations, harmonious interpersonal situations and healthy psychological situations.

Continuing education can use classroom observation, inter-school communication and creating physical or real situations to put learning into the real situation knowledge produced. This would help students actively explore and solve problems to complete the knowledge system construction as well as knowledge understanding and mastering. A harmonious interpersonal situation can be formed by communication between teachers and students to help them get mutual development. 


\section{References}

[1] Houqin Liu, Sha Zhang. Research on the Curriculum of Continuing Education for Preschool Teachers[J] Journal of Higher Correspondence Education (philosophy and social science edition), 2009, (1)

[2] Mehm, F, Gobel, S., Steinmetz, R. Introducing Component-Based Templates Into a Game Authoring Tool. Proceedings Of The European Conference On Games Based Learning. 2011.

[3] A. Sophia, Rita Isaac, Grace Rebekah, K. Brahmadathan, V. Rupa. Risk Factors for Otitis Media among Preschool,Rrural Indian Children[J]. International Journal of Pediatric Otorhinolaryngology . 2010 (6)

[4] Oktay, Ayla,Ramazan, Oya,Sakin, Ahmet. The Relationship between Preschool Teachers''Professional Ethical Behavior Perceptions, Moral Judgment Levels and Attitudes to Teaching. Gifted Education International . 2010. 